\title{
ULTRASONOGRAPHIC EVALUATION OF SMALL, MEDIUM AND LARGE-SIZED JOINTS IN HEALTHY INDIVIDUALS: A COMPARISON BETWEEN YOUTH AND ELDERS
}

\author{
ALEXANDRE LIMA MATOS (UNIVERSIDADE FEDERAL DE SÃO PAULO - UNIFESP, São Paulo, SP, Brasil), \\ Flávia Soares Machado (UNIVERSIDADE FEDERAL DE SÃO PAULO - UNIFESP, São Paulo, SP, Brasil), \\ Rogério Takahashi (UNIVERSIDADE FEDERAL DE SÃO PAULO - UNIFESP, São Paulo, SP, Brasil), José Carlos \\ Nunes Tamashiro (UNIVERSIDADE FEDERAL DE SÃO PAULO - UNIFESP, São Paulo, SP, Brasil), Danielle \\ Freitas (UNIVERISDADE FEDERAL DE SÃO PAULO - UNIFESP, São Paulo, SP, Brasil), Jamil Natour \\ (UNIVERSIDADE FEDERAL DE SÃO PAULO - UNIFESP, São Paulo, SP, Brasil), Rita Nely Vilar Furtado \\ (UNIVERSIDADE FEDERAL DE SÃO PAULO - UNIFESP, São Paulo, SP, Brasil)
}

\section{BACKGROUND}

With aging, there are physiological musculoskeletal changes, which may become confounding factors in ultrasound evaluation. However, studies on this topic are scarce. The aim of this study was to compare the ultrasound findings between healthy young and old.

\section{MATERIALS AND METHODS}

Transversal cohort study in which de ultrasonographic findings of small-, medium- and large-sized joints were compared between a group of healthy youth (GY) and a group of healthy elders (GE). GY was formed by 32 individuals aged under 30 years and GE was formed by 32 individuals aged over 60 years. The articular recesses evaluated were bilaterally (46 articular recesses per individual): 2 nd and 3rd proximal interphalangeal (PIP), dorsal recess and palmar recess; 2nd and 3rd metacarpophalangeal (MCP), dorsal and palmar recess; wrist, radiocarpal (RC), distal radioulnar joint (DRUJ) and ulnocarpal (UC), dorsal recess; elbow (coronoid fossa and olecranon fossa); glenohumeral (axillary and posterior), hip (anterior); knee (anterior); tibiotalar (TT); talonavicular (TN); subtalar (ST) (posterior recess); 1st, 2nd and 5th metatarsophalangeal (MTP), dorsal recess. Quantitative measurements were performed in millimeters $(\mathrm{mm})$ for synovial hypertrophy $(\mathrm{SH})$ and semi-quantitative measurements of 0-3 for $\mathrm{SH}$, synovial blood flow by power doppler (PD) and subchondral bone erosion (BE). A 6-18 MHz transducer was used. A statistical significance of $5 \%$ was considered.

\section{RESULTS}

A total of 64 individuals were studied, with a mean age of 26.2 years (3.2) for GY and 65, 9 anos (4.4) for GY; with 22 (68.8\%) white for GY and 24 (75\%) for GE; being 20 (62.5\%) women in both groups. A total of 2,944 articular recesses $(8,832$ measurements) were studied for semi-quantitative measurements $(\mathrm{SH}=$ $2944, P D=2944$ and BE = 3200). There were several differences between groups $(p<0.05)$, with lower scores in the GY group. The quantitative SH showed difference in recesses: 2MCP; 3MCP; 2PIP; 3PIP; ST, and 5MTP. In the semi-quantitative SH: RC; 3MCP; 2PIP; 3PIP; hip; ST and 2MTP. In semi-quantitative BE: RC; UC; 2MCP; 3MCP; 2PIP; 3PIP; glenohumeral; TT; TN; ST; 1MTP; 2MTP e 5MTP. In PD there was difference only in $2 \mathrm{MCP}$.

\section{CONCLUSION}

Lower ultrasound scores were observed in most joints assessed in young individuals. The differences were more frequent for quantitative measures of SH and, mainly, for BE. In the latter case, in small, medium and large joints. 